\title{
. \\ Health service support of breast feeding - are we practising what we preach?!
}

Sally Beeken, Tony Waterston

Abstract

Objective-To ascertain the attitudes of health professionals and breast feeding mothers to breast feeding and their views on current practice.

Design-Questionnaire to all midwives and health visitors and to breast feeding mothers in Newcastle upon Tyne.

Setting-Maternity units and community in Newcastle upon Tyne.

Subjects-127 hospital midwives, 23 community midwives, 63 health visitors, and 50 first time breast feeding mothers.

Results-Optimum practice guidelines were not followed. $30(60 \%)$ mothers said they were separated from their babies on the first night after birth. 82 (42\%) professionals said that breast fed babies were frequently given water to drink. $28(56 \%)$ babies in the mothers survey had received food or water other than breast milk; 19 of these had been given water. Professionals expressed mainly positive attitudes towards breast feeding in general but less positive attitudes to specific issues such as the beneficial effects on child health and the value of voluntary organisations in breast feeding promotion and management.

Conclusions-Although many health workers are in favour of breast feeding there is conflict among the professions working most closely with breast feeding mothers. Good breast feeding support requires closer attention to monitoring hospital practices and continued training on good lactation management.

\section{Introduction}

The survey of breast feeding in Great Britain carried out for the Office of Population Censuses and Surveys in 1985 showed that there had been no significant increase in the breast feeding rate since the previous survey in 1980.' There is little evidence to suggest there has been an increase since. Indeed, Emery and colleagues found a decline between 1984 and 1988 in the percentage of mothers intending to breast feed. In 1987 a study in Newcastle upon Tyne found breast feeding rates of $39 \%$ initially and $20 \%$ at six weeks (B Bose, unpublished data).

After the disappointing lack of improvement in breast feeding rates in the beginning of the decade, the remainder of the 1980s saw an upsurge of activity promoting breast feeding, including the launch of the Joint Breastfeeding Initiative ${ }^{3}$ and the Royal College of Midwives' booklet Successful Breastfeeding. ${ }^{4}$ In addition, epidemiological evidence for the benefits to children's health from breast feeding in the United Kingdom was published. ${ }^{5}$ Laboratory evidence to explain these benefits continues to accumulate. Recently, the protection afforded to premature babies against necrotising enterocolitis was established. ${ }^{6}$

As part of the national breast feeding drive a breast feeding campaign aimed at health care professionals took place in Newcastle. Health workers play a key role in immunisation uptake ${ }^{7}$; similarly, they are thought to have an important part to play in the initiation and success of breast feeding. With the necessary ethica approval we carried out a study in early 1990 that aimed at establishing current attitudes to breast feeding among midwives and health visitors and using the information gathered to improve professionals practice and thereby increase the initiation and duration of breast feeding. We report the results of the initial survey.

The basis for comparison was a code of practice later adopted by the Newcastle Breastfeeding Promotion Group, which derived from accepted internationa norms ${ }^{89}$ and contained the following guidelines:

- If the mother plans to breast feed, the baby should be put to the breast immediately after birth

- Breast fed babies should be kept with the mother (room in) and not put in a nursery at nigh

- Breast fed babies should not normally be offered complementary feeds or water

- There should be no advertising or promotion of infant formula on health services premises.

\section{Method}

A questionnaire was sent to all available midwives and health visitors in Newcastle upon Tyne, a total of 213 workers (127 hospital midwives, 23 community midwives, and 63 health visitors) in an area with 3700 births a year. A total of 54 hospital midwives were excluded because they had been used in the pilot study, were working in special care, or were not at work at the time. Six community midwives and four hospital midwives were excluded because they had been used in the pilot study or were not at work at the time. The questionnaire had been piloted with a random sample of health visitors and midwives and was designed to elicit hospital practices and professionals' attitudes. With the questionnaire all professionals received an explanatory letter requesting their participation in the study and a prepaid envelope for their reply. The information received was confidential but not anonymous, thus enabling follow up of nonresponders.

The questionnaire focused on activities promoting infant feeding, use of the Royal College of Midwives' booklet, hospital practices concerning breast feeding, encouragement of breast feeding, helping with sore nipples and insufficient milk, influences on a mother's feeding choice, and professionals' attitudes to breas feeding. In addition, demographic data were collected age, year of qualification, number of own children, and type of feeding and feeding problems encountered.

To complement the questionnaire for professionals, primiparous women who had ever breast fed were
Correspondence to:

Dr Waterston.

BMf 1992;305:285-7 


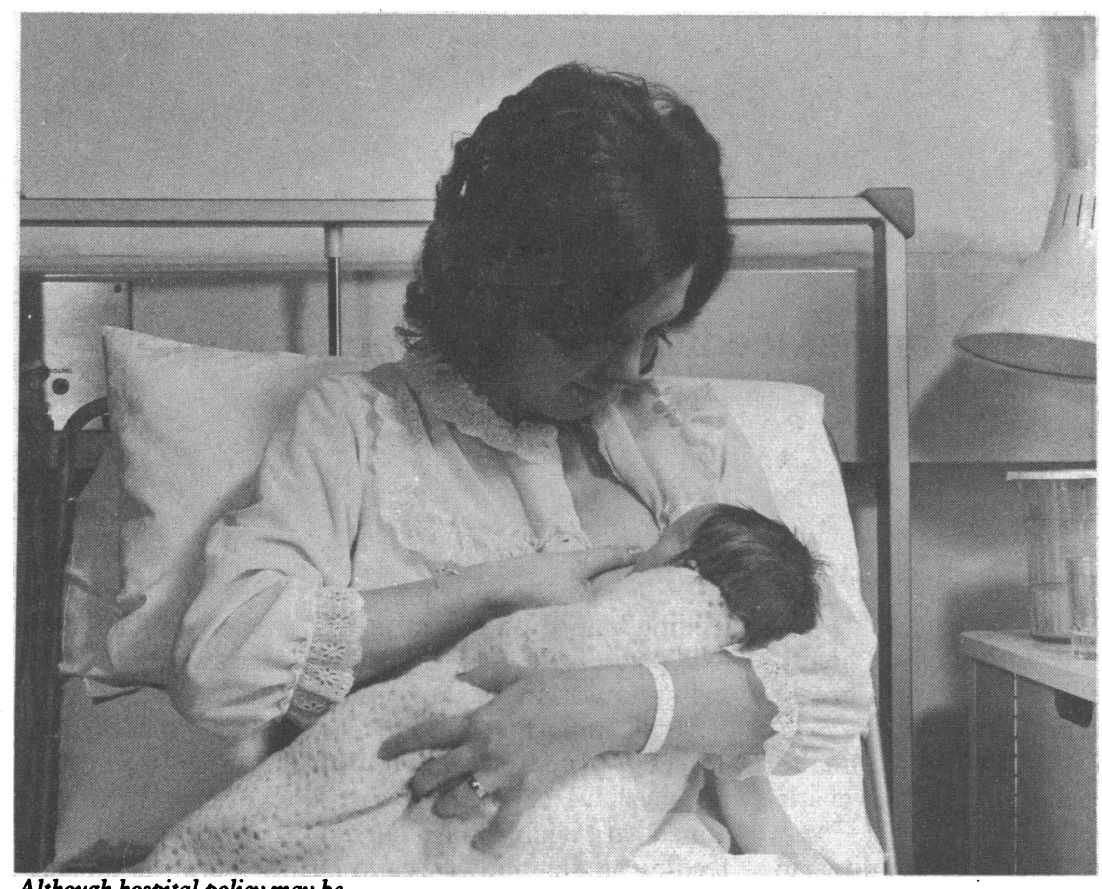

Although hospital policy may be in line with current thinking on aiding the establishment and continuation of breast feeding, actual practice may be quite different asked about their feeding experiences. Only first time mothers were chosen to ensure that previous experiences did not influence their response. All primiparous women delivering in the Newcastle maternity units during a five week period (a total of 90) received a questionnaire along with the other information routinely given at the time of hospital discharge. Mothers were asked about the information they had received about infant feeding, parentcraft classes, their stay in hospital, and problems they encountered. Demographic data were also collected, including their age, ethnic origin, and previous education. Replies were anonymous and follow up of non-responders was not possible.

Questionnaires contained both precoded and postcoded questions. The statistical package for the social sciences (SPSS-X) was used for analysis.

\section{Results}

The questionnaire was returned by 118 of 127 hospital midwives $(92 \%), 21$ of 23 community midwives (91\%), and 58 of 63 health visitors $(92 \%)$.
Fifty of 90 first time breast feeding mothers $(55 \%)$ responded.

Results from the questions concerning hospital practices and professional attitudes are reported here. Almost all (40/41) respondents replying "don't know" were working in the community.

Table I shows practices related to breast feeding in hospital. Rooming in (apart from the first night) was said to occur very frequently or frequently by $85 \%$ of respondents. Dextrose, glucose, and top up bottle feeds were infrequently or never given to breast fed babies $(74 \%)$. However, $42 \%$ of respondents said that babies were frequently or very frequently given water. Forty eight per cent of professionals said test weighing of breast fed babies never occurred. Eighty one per cent said that babies were very frequently or frequently offered the breast immediately after birth.

Thirty five of the 50 mothers had experienced problems with breast feeding. All of them had asked for advice; 27 had asked a hospital midwife. Twelve mothers had stopped breast feeding by three weeks; nine of these stopped in the first week. The mos common reasons given for stopping were baby not getting enough milk; could not tell how much the baby was getting; mother was too ill; baby was ill or rejected breast milk; engorgement; and painful or sore nipples.

Thirty three mothers said their babies went to the nursery on their first night. Reasons included being told that the baby would be returned for feeds (seven) mother needed sleep (19), caesarean section (five) convenience or routine (five), baby wouldn't settle (three). Twenty eight mothers reported that thei babies had received food or drink other than breas milk while in hospital: 19 received water, six formula and three both. In six cases the mother suggested the baby have additional food or fluids. Fifteen mothers had put their baby to the breast in half an hour of birth, 26 in 11/2-2 hours, three in 2-4 hours, and 19 after fou hours. The baby was fed on demand by 43 mothers, when the mother wanted to by two, and every three hours by two.

Professionals were asked to indicate how much they agreed or disagreed with the statements shown in table II. Although many professionals $(71 \%)$ agreed that lay organisations should be more widely adver tised, fewer $(45 \%)$ agreed that they should be allowed into hospital to help mothers with breast feeding. Most of those who did agree worked in the community. Many professionals $(92,47 \%)$ disagreed with the

TABLE I-Hospital practices. Answers of 197 health workers to the question: "Please indicate how often the following practices occur in the hospital where you work as a midwife or the hospitals that are in your area as a health visitor." Values are percentages (numbers)

\begin{tabular}{lcccccc}
\hline & Very frequently & Frequently & Infrequently & Never & Don't know & Missing data \\
\hline Baby is taken to the nursery on the first night back on the ward & $16(32)$ & $31(62)$ & $27(54)$ & $1(2)$ & $20(40)$ & $4(7)$ \\
Breast fed babies given dextrose or glucose & $1(1)$ & $4(7)$ & $13(26)$ & $61(121)$ & $17(34)$ & $4(8)$ \\
Breast fed babies given top up bottle feeds & 0 & $8(16)$ & $64(127)$ & $9(17)$ & $15(30)$ & $4(7)$ \\
Test weighing of breast fed babies & 0 & $1(2)$ & $25(50)$ & $48(95)$ & $21(41)$ & $5(9)$ \\
Nipple shields used to help baby “fix" & $1(1)$ & $18(36)$ & $54(107)$ & $10(19)$ & $13(25)$ & $5(9)$ \\
Breast fed babies given water to drink & $4(8)$ & $38(74)$ & $30(60)$ & $11(21)$ & $11(21)$ & $7(13)$ \\
Baby offered the breast immediately after birth & $44(87)$ & $37(72)$ & $2(4)$ & $13(25)$ & 0 \\
Apart from the first night rooming in is practised & $64(127)$ & $20(39)$ & $1(2)$ & 0 & $12(23)$ & $3(6)$ \\
\hline
\end{tabular}

TABLE II - Health professionals' ( $n=197$ ) attitudes to breast feeding. Values are percentages (numbers)

\begin{tabular}{|c|c|c|c|c|c|c|}
\hline Statement & Strongly agree & Agree & Not sure & Disagree & Strongly disagree & Missing data \\
\hline $\begin{array}{l}\text { Women are overloaded with information about infant feeding } \\
\text { Lay organisations such as NCT or LLL should be more widely }\end{array}$ & $4(8)$ & $17(34)$ & $10(19)$ & $61(120)$ & $6(12)$ & $2(4)$ \\
\hline $\begin{array}{l}\text { advertised } \\
\text { Milk company advertising should be banned in antenatal clinics } \\
\text { Lay organisations should be able to help women in hospital with }\end{array}$ & $\begin{array}{l}17(33) \\
14(27)\end{array}$ & $\begin{array}{l}54(106) \\
27(54)\end{array}$ & $\begin{array}{l}15(29) \\
11(22)\end{array}$ & $\begin{array}{l}13(26) \\
43(84)\end{array}$ & $\begin{array}{l}1(2) \\
4(8)\end{array}$ & $\begin{array}{l}1(1) \\
1(2)\end{array}$ \\
\hline $\begin{array}{l}\text { breast feeding } \\
\text { There is no need to wean a baby from the breast before } 4 \text { months } \\
\text { Breast fed babies are healthier babies } \\
\text { Breast feeding should stop if pregnancy occurs } \\
\text { Breast milk is better for the baby than formula milk } \\
\text { The type of feeding affects the health of the baby }\end{array}$ & $\begin{array}{l}13(25) \\
36(71) \\
22(43) \\
2(3) \\
56(110) \\
15(30)\end{array}$ & $\begin{array}{l}31(62) \\
47(92) \\
43(85) \\
21(42) \\
39(77) \\
37(73)\end{array}$ & $\begin{array}{r}13(26) \\
7(14) \\
6(12) \\
22(43) \\
0 \\
9(17)\end{array}$ & $\begin{array}{r}29(57) \\
7(13) \\
27(54) \\
45(89) \\
2(3) \\
34(66)\end{array}$ & $\begin{array}{l}11(22) \\
1(1) \\
1(1) \\
8(16) \\
4(7) \\
3(6)\end{array}$ & $\begin{array}{l}3(5) \\
3(6) \\
1(2) \\
2(4) \\
0 \\
3(5)\end{array}$ \\
\hline
\end{tabular}

$\mathrm{NCT}=$ National Childbirth Trust $\mathrm{LLL}=\mathrm{La}$ Lèche League. 
statement that milk company advertising should be banned in antenatal clinics. Most (96\%) agreed that breast milk is better for babies than formula milk, but $28 \%$ disagreed with the statement that breast fed babies are healthier babies and $37 \%$ disagreed with the statement that the type of feeding affects the health of the baby. A total of $23 \%$ felt that breast feeding should stop if pregnancy occurs.

\section{Discussion}

The importance of certain hospital practices for successful breast feeding is well documented and widely accepted..$^{10-13}$ Comparison of the surveys of the professionals and the mothers showed that although rooming in is said to occur frequently or very frequently by professionals, on the first night $66 \%$ of mothers and babies were separated. Professionals stated that glucose, dextrose, and formula is infrequently given; however, of those babies receiving food or fluid other than breast milk, a third had received formula.

Professionals stated that water is frequently given, and this is corroborated by the mothers' survey: half the breast fed babies had received water. Although professionals said that immediate offering of the breast frequently occurs, less than one third of mothers had put their baby to the breast within half an hour of birth

Despite the evidence that mother-infant separation and additional food and fluids for breastfed babies is undesirable, these practices frequently occurred in the hospitals surveyed. Although the practices were initiated by the mother, in some cases a professional may have suggested a practice considered to be deleterious to successful breast feeding. We postulate that this may occur when the professional's own belief as to the efficacy of beneficial practices is weak or her attitude to breast feeding is negative.

This study has implications for application of hospital policy. Although policy may be in line with current thinking on aiding the establishment and continuation of breast feeding, actual practice may be far removed from this. Furthermore, if professionals are unconvinced of the advantages of breast feeding they may feel less inclined to carry out a policy whose aims are to aid its success. Careful monitoring of ward practice and breast feeding may bring policy and practice into line.

In addition, training of health professionals caring for breast feeding mothers requires consideration. This study suggests that there is some ambivalence towards the benefits of breast feeding. The superiority of breast milk is unquestioned, but professionals are less prepared to agree with specific reasons why this is the case. The thinking behind this is unclear, although the fear of making bottlefeeding mothers feel guilty or inferior by extolling the virtues of breast milk is a possibility.

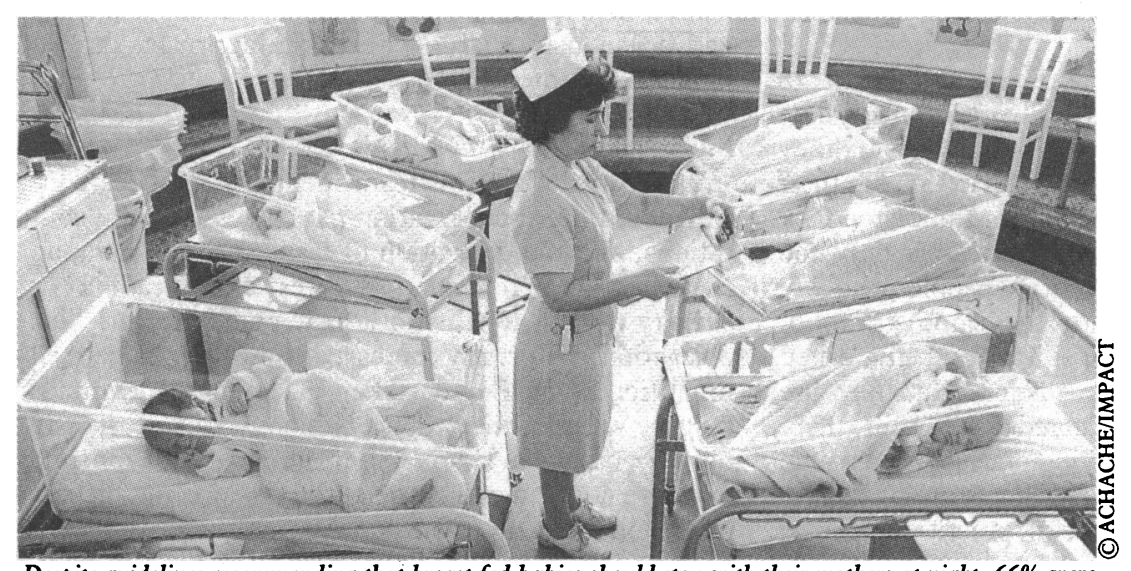

Despite guidelines recommending that breast fed babies should stay with their mothers at night, $66 \%$ were separated from their mothers on their first night

\section{Baby friendly hospitals: code of practice}

Unicef will designate any hospital that follows the 10 steps in the code of practice as "baby friendly."

(1) Have a written breast feeding policy-routinely communicated to all health staff.

(2) Train all health staff in skills to implement this policy.

(3) Inform all pregnant women about the benefits and management of breast feeding.

(4) Help mothers initiate breast feeding within half an hour of birth.

(5) Show mothers how to breast feed, and how to maintain lactation even if they should be separated from their infants.

(6) Give newborn infants no food or drink other than breast milk, unless medically indicated.

(7) Practise rooming in (allow mothers and infants to remain together) 24 hours a day.

(8) Encourage breast feeding on demand.

(9) Give no artificial teats or pacifiers (also called dummies or soothers) to breast feeding infants.

(10) Foster the establishment of breast feeding support groups and refer mothers to them on discharge from the hospital or clinic.

Such a high proportion of mothers experiencing problems and stopping breast feeding indicates that all is not well in hospital management of breast feeding. Though the response rate from mothers was low, there is no reason to suspect that the women who replied were unrepresentative. The high attrition rate in the early weeks ( $18 \%$ in the first 10 days) is particularly disturbing and corresponds with national trends. ${ }^{3}$ Local policy guidelines on support of breast feeding mothers should be published and monitored; there should be greater emphasis on the updating of health professionals in order to increase their awareness of breast feeding issues, promotion, and management. Involvement of lay groups (National Childbirth Trust, La Lèche League) in supporting breast feeding mothers at the time of discharge from hospital is also desirable. These points are included in the "baby friendly hospital" initiative of Unicef (box), ${ }^{8}$ which should be widely publicised in Britain.

We are grateful to the nursing officers, midwives, and health visitors who cooperated closely with the study, and to the breast feeding mothers of Newcastle. The work is ongoing, and training is rectifying many of the defects found in the study.

This study was funded by the Health Promotion Research Trust. It was conducted as part of a BMedSci dissertation by Sally Beeken.

1 Martin J, White A. Infant feeding 1985. London: HMSO, 1988.

2 Emery JL, Scholey S, Taylor EM Decline in breastfeeding. Arch Dis Childhood 1990;65:369-72.

3 Department of Health. Report of a conference to launch a joint breastfeeding initiative. London: DoH, 1988.

4 Royal College of Midwives. Successful breastfeeding-a practical guide for midwives. Oxford: Holywell Press, 1988.

5 Howie P, Forsyth J, Ogston S, Clark A, duFlorey C. Protective effect of breas feeding against infection. BMF 1990;300:11-6.

6 Lucas A, Cole T. Breastmilk and neonatal necrotising enterocolitis. Lance 1990;336:1519-23.

Wells N. Immunisation-where do we go from here? In: Macfarlane J, ed. Progress in child health. Vol 3. London: Churchill Livingstone, 1987.

8 Grant J. State of the world's children 1992. New York: Unicef, Oxford University Press, 1992:44.

9 Jelliffe DB, Jelliffe EFP, eds. Programmes to promote breastfeeding. Oxford: Oxford Medical Publications, 1988

10 Salariya E, Easton P, Cater J. Duration of breastfeeding after early initiation and frequent feeding. Lancet $1978 ; \mathrm{ii}: 1141-3$.

11 Bloom K, Goldbloom R, Robinson S, Stevens F. Factors affecting the continuance of breastfeeding. Acta Paed Scand 1982;300(suppl):9-14.

12 Frank D, Wirtz S, Sorenson J, Heeren T. Commercial discharge packs an breast feeding counselling: effects on infant feeding in a randomised trial. Pediatrics 1987;80:845-54.

13 Cruse P, Yudkin P, Baum J. Establishing demand feeding in hospital. Arch Dis Childhood 1978;53:76-8. 